\title{
V. Bezdelov
}

Master of Information systems

vladislavbezdelov@gmail.com, orcid.org/0000-0001-7438-3575

Karaganda State Technical University, Kazakhstan

\section{A. Kalinin}

Acting of head of department Information and Computing systems, $\mathrm{PhD}$ in Power Engineering

a.kalinin@kstu.kz, orcid.org/0000-0003-4699-7240

Karaganda State Technical University, Kazakhstan

\section{B. Sultanova}

Candidate of Pedagogical sciences, Assistant professor of Department of Information and Computing systems

bk.sultanova@mail.ru, orcid.org/0000-0003-1587-650X

Karaganda State Technical University, Kazakhstan

\section{EFFECTIVE MANAGEMENT AND OPTIMIZATION OF BUSINESS PROCESSES}

\begin{abstract}
This article discusses the problems of introducing an effective business, as well as optimizing business processes. Various approaches to managing and optimizing business processes are analyzed. The reasons for which it is necessary to improve the process and each component of this process are identified and described. Two main approaches to improving business processes are considered: functional and approach, the main differences between them, as well as the advantages and disadvantages of each of them are demonstrated. Any process has a life cycle, thanks to which it follows; the article considers the life cycle of six sigma. Based on the material studied, methods for improving business processes are proposed, and the role of the leader is examined, and concepts such as creative management and a creative manager are examined and what their role is in modern business. Any life cycle needs modeling, timely improvement, so that the company can get good results, so managers and chief managers must follow the simple rules discussed in the article in order to simulate the business process "as is" and "as it should be", you can use the Business Process Management Notation and special software designed for this. The general conclusion of the article is that each company should choose its own approach and method of optimizing business processes based on general principles.
\end{abstract}

Key words: business processes, processes, process management, optimization.

\section{Introduction}

Business process management (BPM) is a systematic approach to management aimed at improving the organization's activities and its processes. This approach enables the organization to define its processes, as well as improve quality.

In business processes, a set of logically interconnected actions or tasks is understood, the implementation of which leads to the expected result. Almost all organization processes can be attributed to the business process.

The main goal of managing a business process is to bring processes in line with the goals of the organization. So that the results of the process lead to the achievement of business goals. 


\section{What is a business process?}

The basis of business process management is documentation on their description, optimization and regulation. These sources affect all employees who are involved in a particular process. Chief managers are interested in improving the manageability and transparency of work processes. Mid-level managers want to see the boundaries of their activities and the results for which they are responsible, and the performers need clear working rules. When creating and introducing a new project, it is necessary to consider all layers of employees.

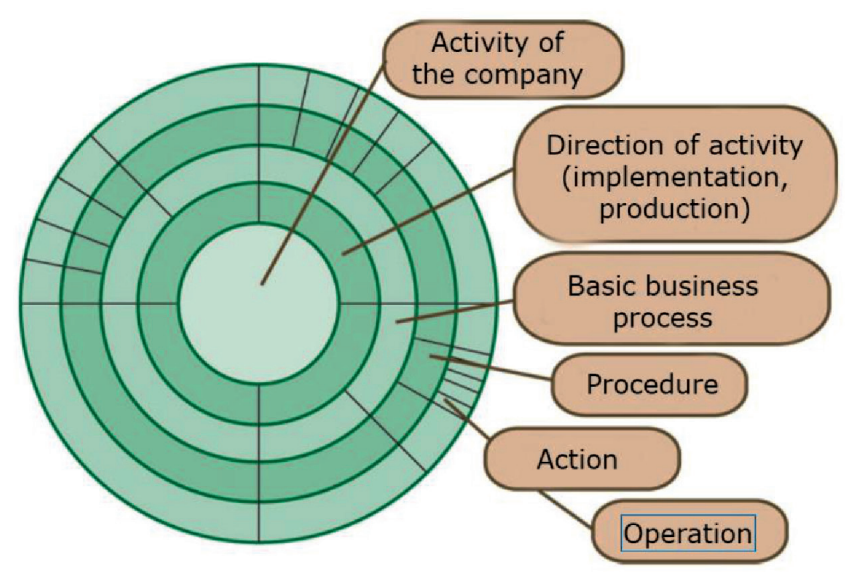

Fig. 1. Dismantle business process details

Figure 1 shows the levels of detail of business processes:

- Operation - an employee's activity that is performed automatically, without control.

- Action - sequentially performed operations, after which control is carried out.

- Procedure - sequentially performed actions that are carried out by a specific employee. The result of the procedure will be a document or product.

- A basic level business process is a sequence of procedures that are carried out by various executors. The result of which is a significant result for the company.

- Direction of activity - one or more business processes of a basic level.

\section{How to determine the relevance of business process management?}

If a company is at a development stage, then it does not make sense for a small company to strictly structure the business process, since competitiveness comes first, and the framework that is set for process management can eradicate flexibility and quick adaptation to various situations, which will come to that the company may be lost against its other competitors.

Subsequently, after the company began to grow, it is necessary to resort to management, thanks to which each employee will perform his functions, managers will control the process and their subordinates. But in this case, it is worth noting that the company has not a dozen employees, but many.

Only those processes that have been formed and are repeated over time are subject to business process management. In a company where a large number of people need to try different process options and choose other approaches for implementing this business process.

Some terms need to be clarified in order to understand exactly what a process is:

- The task is the work that is performed once in a short time. This task is performed by one employee according to some rules.

- Function - the regularly performed work of one performer according to the established rules, which are known in advance.

- The project is a repeatedly performed work by many employees, which takes a long time. 
- The process is the regularly performed work of many performers according to well-known rules and algorithms.

Based on the above terms, managing a task or project does not make sense, since this performance of work is one-time and the regulation of such activities does not carry any special significance. The process leads to a result that is significant for the entire enterprise as a whole, and not in particular for one department.

Many manuals recommend the following points in order to get changes in the business process:

- Modeling processes "as is" (Fig.2).

- Modeling processes "as it should be" (Fig.3).

- Regulation of the process.

- Implementation of changes.

In this case, the processes cannot be rearranged, since the modeling of the processes "as it should be" is impossible without the "as is" scheme, and the introduction of changes should be carried out only after there is a regulation according to which everything should change [1].

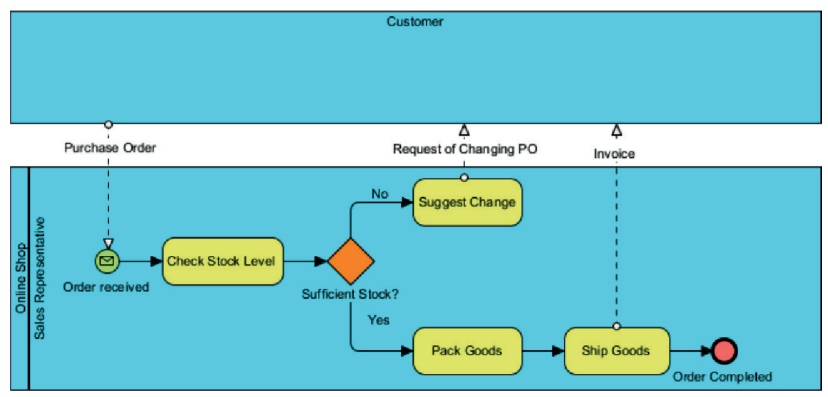

Fig. 2. Modeling processes "as is"

Many companies resort to the help of people from outside, namely consultants. This action is not effective for the company itself, and carries a waste of money that could have been avoided. This is due to the fact that consultants are people from the outside and do not see the problem as they can be seen by the executors of a particular process, as well as their leaders. It is also worth adding that people from the outside may not have the proper experience in working in that area and have no idea how it should work. Therefore, the strategy described above can only be carried out by company managers who are interested in the growth and progress of the company. The process will be regulated by the introduction of new rules and decisions that will be developed and implemented by the leaders themselves. Thus, the role of a consultant in this case is to give managers the necessary knowledge and help in practice with the description, optimization and management of the business process. In this case, managers acquire new skills and competencies, and the process requires minimal investment.

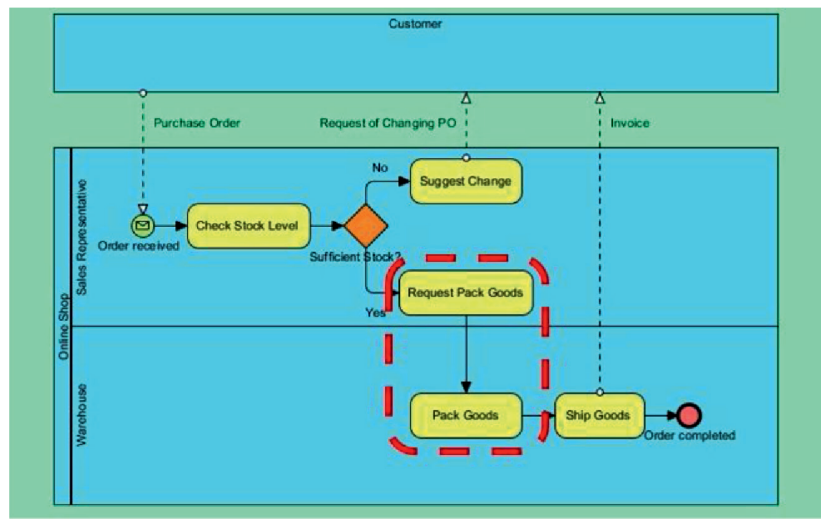

Fig. 3. Modeling processes "as it should be" 


\section{How to determine the relevance of business process management?}

The organization may adopt a functional management approach that considers the company as a set of departments, each of which performs certain functions. In this case, the teams do everything necessary to increase their performance indicators, but this will not be reflected on the result of the company, which may lead to disagreement. In this approach, it is worth highlighting that there is a delegation of authority using functions. A functional approach is used to manage regularly recurring activities.

In contrast to the functional approach, the process focuses on a set of basic business processes. The main business processes are those due to which the company makes a profit, and the supporting processes are those without which the main ones cannot exist. Thus, in this approach, we can distinguish that each process of the company has its own goal, but at the same time it is aimed at the general ultimate goal of the company, there is an owner (manager) who manages resources and is responsible for the implementation of the process, as well as a quality control system indicators.

As defined by J. Harrington: "Business Process Improvement is a methodology based on step-by-step improvement of administrative and support processes using approaches such as [2]:

- Rapid Decision Analysis Technique (FAST);

- Process benchmarking (Process Benchmarking);

- Redesigning the process;

- Process reengineering (RBP).

Benchmarking deserves special attention in the context of managing business processes and implementing their optimization. A study of the most popular Management Tools in 2011 (Fig.4), conducted by the consulting company Bain \& Company, starting in 1993 annually, indicated that benchmarking is the most popular tool in managing the company today. Business process reengineering is included in the TOP-20 tools for managers to use.

Table 1 describes the pros and cons of a functional and process approach to managing business processes.

Figure 6: Top 10 most used tools

\begin{tabular}{|c|c|c|c|c|c|}
\hline & Global & North Americe & Europe & Asia & Latin Amerika \\
\hline Benchmarking & 1 & 3 & 1 & 4 & 3 \\
\hline Strolegic planning & 2 & 2 & 3 & 2 & 16 \\
\hline Mission and vision stotements & 3 & 4 & 561 & 3 & $1(1)$ \\
\hline Customer relotionship management & 4 & 1 & 2 & 1 & 6 \\
\hline Outsourcing & 5 & 6 & 561 & 5 & 4 \\
\hline Bolanced scorecord & 6 & $12(1)$ & 8 8*1 & $10+11$ & 5 \\
\hline Change manogement progroms & 7제 & 9 & 4 & $8(t)$ & 9 \\
\hline Core competencies & 개 & 5 & 8(1) & 6 & 10:H \\
\hline Strotegic olliances & 9 & 7 & 7 & 86 & 8 \\
\hline Cuslomer segmentation & 10 & $15(n)$ & 12 & 10N & 7 \\
\hline
\end{tabular}

Nowa W - Hed

Sovice: Boin uner

Fig. 4. Popular management tools 
Table 1. Comparative characteristics of existing approaches to enterprise management

\begin{tabular}{|c|c|c|}
\hline \multirow{2}{*}{ Attribute } & \multicolumn{2}{|c|}{ Approach } \\
\hline & Functional & Process \\
\hline Entity & $\begin{array}{l}\text { The enterprise is considered as a mechanism } \\
\text { with a set of functions distributed among } \\
\text { departments }\end{array}$ & $\begin{array}{l}\text { The enterprise is represented by a set of } \\
\text { processes that go through all departments } \\
\text { and involve all the services of the enterprise }\end{array}$ \\
\hline Object & Department, organizational structure & Business process \\
\hline Disadvantages & $\begin{array}{l}\text { 1) lack of interest of employees } \\
\text { in the end result, they are not focused on the } \\
\text { goals of the enterprise; } \\
\text { 2) the exchange of information between } \\
\text { departments is complicated, which leads } \\
\text { large overhead costs, long periods of } \\
\text { development of management decisions; } \\
\text { 3) it takes a lot of time to implement } \\
\text { managerial impact on the production process; } \\
\text { 4) authoritarian management, etc. }\end{array}$ & 1) the interdependence of decision makers \\
\hline Advantages & $\begin{array}{l}\text { 1) conflict-free decision-making process, } \\
\text { excluding the interdependence of decision- } \\
\text { makers }\end{array}$ & $\begin{array}{l}\text { 1) focus on the end result; } \\
\text { 2) achievement of high performance; } \\
\text { 3) the flexibility to respond to external and } \\
\text { internal changes; } \\
\text { 4) quality control of the process, not the final } \\
\text { product; } \\
\text { 5) motivation; } \\
\text { 6) efficiency; } \\
\text { 7) democratic governance system }\end{array}$ \\
\hline
\end{tabular}

Business process management uses the following approaches:

- Comprehensive, understandable and documented standardization of processes, which includes the creation of a set of standardized processes and the ability to customize them to changing conditions;

- Continuous improvement of processes, including daily monitoring, measurement, analysis and change of processes;

- Application of information technologies and software, including modeling of business processes, use of CASE tools, automation of business processes and their optimization based on information technology.

The conclusion that can be drawn by analyzing the table above will sound something like this: if you want to create an organization that quickly adapts to changes in the external environment and is aimed at meeting customer needs through the release of quality products, where the people working in the company are a strategic asset, your the task is to introduce process management.

\section{Business process management cycle}

The business process management cycle follows the principles of continuous improvement. Based on these principles, management consists of repeating steps. Each stage includes several phases. During each phase, a specific set of actions is performed. In general, the stages of business process management are similar to the DMAIC 6 sigma methodology cycle (Fig.5) [3]. 
Business process management consists of the following phases:

- The first phase is the definition of the process. At this phase, the process is simulated in the initial state and in the desired state ("as is" and "as it should be" models are developed) [1].

- The second phase is process analysis. At this phase, various options for the process are determined, simulation is carried out. As a result, optimal methods for improving the business process are determined.

- The third phase is the implementation of the changes. In this phase, the selected improvement methods are applied to the process. The introduction of changes to the process.

- The fourth phase is process monitoring. At this phase, periodic monitoring of the process is carried out according to certain indicators.

- The fifth phase is process optimization. At this phase, the actual results obtained by changing the process are compared with the desired model ("as it should be") and the next improvement cycle begins.

If the indicated phases of business process management must be applied to several processes, a preliminary phase is performed. During the preliminary phase, the necessary processes are selected and priorities for their change and improvement are set.

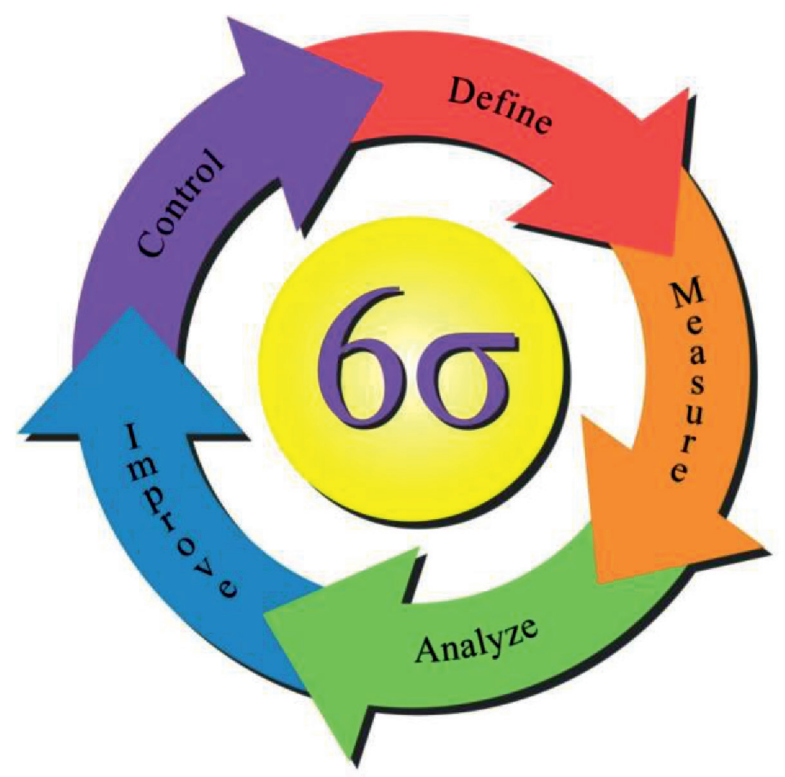

Fig. 5. Six sigma methodologies

\section{Scheme modeling, the concept of a creative manager and a language for modeling business processes}

The basis of this method is the business process that exists today in the company. To see how it works, you need an "as is" scheme. If this scheme does not exist, then the possibility of analyzing the process will be impossible. In this case, you need to describe it in as much detail as possible, divide the entire process into components in order to see all the bottlenecks who is responsible for them.

Modeling the scheme should be clear not only to managers, but also to performers. After all, it is the leaders of processes or enterprises that organize the activities of units and personnel. Therefore, the simpler the description of the business process and their analysis, the better and better the work with data. 
After the analysis has been carried out over the "as is" scheme, the next step is the developed model of the "As It Should Be" business process. In this model, a solution should be presented on how to avoid problem areas and improve the business process, but other components should not be worsened. After all, solutions for improvement are not unambiguous and always improving in one place, you are guaranteed to worsen in another [4].

There is a practice where other companies learn from their competitors or those with a similar business process. But this option can be doomed to failure, since two different enterprises cannot work according to the same scheme. There are many practices that are offered, in this case, you must first assess all the advantages and disadvantages of this approach and adopt only what is necessary for your process and meets your needs.

"Optimization" includes finding a solution that will give the company the greatest efficiency and growth. As a rule, such a solution is to analyze the experience gained by the company. But it is important to note that it is analysis, and not copying experience from other companies.

To improve business processes, you must follow these rules:

- Managers need to track the activities of the process in the form of a metric with which you can evaluate the effectiveness of the activity.

- It is necessary to systematically invest in processes. Updating the technological component to increase productivity and increase work efficiency.

- It is necessary to use Business Process Improvement, which contain standards for continuous improvement of the business process.

BPI offers important benefits for any organization. But in order to take advantage of these advantages, it is necessary to approach with all severity making efforts to improve the process. Six phases are distinguished to improve relatively complex processes:

- Plan: choose an existing business process that needs to be improved, determine its scope and assemble your team.

- Analysis: carefully examine the process that will be improved.

- Redesign: determine what changes need to be made to the target process.

- Acquisition of resources: obtain personnel, equipment, and other resources necessary to make changes to the process.

- Implementation: implement process changes.

- Continuous improvement: make further changes as necessary [4].

To date, there is the concept of "creative manager". Previously, the manager was just an executor, but with the development of new technologies there was a need for the development of managers who can manage the process and personnel. The basis of such a manager is the generation of new ideas, research and the adoption of strategically sound decisions. The concept of creative education is used widely throughout the world, but is rarely used in Kazakhstan. Such an education helps to analyze problems; thinking and management skills are developing. Thus, the "creative manager" becomes not just employees fulfilling their duties, but also to some extent the boss, researcher and creator. Such people have developed a strategic type of thinking. This type of difference from research thinking, with the help of which a person can solve the problem here and now based on the obtained and reliable facts, the strategic one helps to look at the problem now, solve it and look into the future for its possible outcomes, when implementing certain solutions.

BPMN (Business Process Management Notation) - a business process modeling language is a formalization and visualization of a business process. With it, you can describe the work of an activity using graphic elements. This language is used to build models "as is" and "as it should be" [5]. Figure 6 shows a business process using BPMN. 


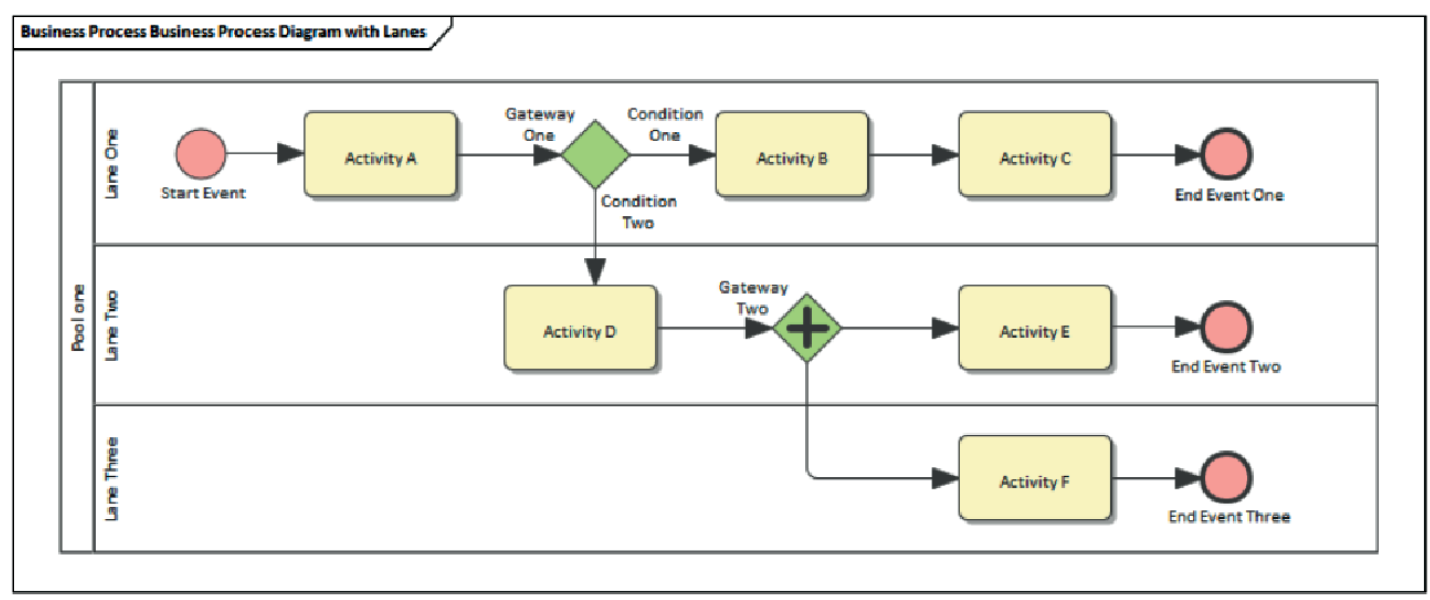

Fig. 6. Business Process Using BPMN

\section{Conclusion}

This article examined the main aspects of effective management and optimization of business processes. Based on which it can be concluded that today the most relevant and common method for optimizing business processes is the process approach, which helps the company achieve its goals due to the small goals that build teams within this organization. But it is worth noting that each company should choose its own process management approach, because for each company it will have its own and work in its own way. The cycle of the business process according to the six sigma methodology is considered, as well as the modeling of schemes as is and as it should be, the concept of a creative manager is considered and what a leader should be like today.

\section{References}

1. Aagesen, Gustav \& Krogstie, John. (2015). 'BPMN 2.0 for Modeling Business Processes. Handbook on Business Process Management 1: Introduction, Methods, and Information Systems.' pp 219-250.

2. Harrington, H.J. (1991), Business Process Improvement: The Breakthrough Strategy for Total Quality, Productivity and Competitiveness, McGraw-Hill, New York, NY

3. Smętkowska Monika, Mrugalska Beata (2018) 'Using Six Sigma DMAIC to Improve the Quality of the Production Process: A Case Study', Procedia - Social and Behavioral Sciences, vol. 238, pp. 590-596.

4. Harvard Business Press (2012) 'Improving Business Processes. Expert Solutions to Everyday Challenges', pp. 3-97.

5. Silver Bruce (2009),'BPMN Method and Style: A levels-based methodology for BPM process modeling and improvement using BPMN 2.0', Cody-Cassadi Press. 